\title{
Cervical cancer and the HPV link: Identifying areas for education in Mexico City's public hospitals
}

\author{
Tess Aldrich, MSc, ${ }^{(1)}$ Sarah Landis, MPH, ${ }^{(2)}$ Sandra G. García, ScD, ${ }^{(3)}$ Davida Becker, MSc, ${ }^{(4)}$ \\ Patricio Sanhueza, MD, ${ }^{(5)}$ Anjarath Higuera, MD. ${ }^{(6)}$
}

\author{
Aldrich T, Landis S, García SG, Becker D, \\ Sanhueza P, Higuera A. \\ Cervical cancer and the HPV link: \\ Identifying areas for education \\ in Mexico City's public hospitals. \\ Salud Publica Mex 2006;48:236-243.
}

\begin{abstract}
Objective. To assess Mexico City physicians' knowledge and practices regarding cervical cancer and human papillomavirus (HPV) to compare obstetricians/gynecologists (ob/gyns) and general practitioners (GPs) on these variables. Material and Methods. In April 2003, I87 ob/gyns and GPs working in I 5 hospitals affiliated with the Federal District Secretary of Health (SSDF) completed a self-administered questionnaire. Pearson's chi-square tests were used to compare ob/ gyns and GPs on outcome variables. Results. Nearly all providers (93\%) identified HPV as the principal cause of cervical cancer. Ob/gyns had more detailed knowledge about HPV than GPs and were more likely to have heard of common oncogenic strains $(p=.000)$. Sixteen percent of all physicians incorrectly stated that Pap tests should be performed every six months regardless of previous results, and 17\% recommended hysterectomy as an option for treating mild or moderate dysplasia. Conclusions.While SSDF physicians had basic knowledge about the cervical cancer-HPV link, screening and management norms are priority areas for educational interventions.
\end{abstract}

Key words: cervical cancer; human papillomavirus; physicians; Mexico
Aldrich T, Landis S, García SG, Becker D,

Sanhueza P, Higuera A.

El cáncer cervicouterino y su relación con el VPH:

identificación de temas de actualización en hospitales públicos de la Ciudad de México.

Salud Publica Mex 2006;48:236-243.

\section{Resumen}

Objetivo. Evaluar el conocimiento y las prácticas de los proveedores de servicios de salud en la Ciudad de México sobre el cáncer cervicouterino y el virus del papiloma humano (VPH); comparar a este respecto a ginecoobstetras (GO) y médicos generales (MG). Material y métodos. En abril del 2003, 187 GO y MG empleados en I5 hospitales afiliados a la Secretaría de Salud del Distrito Federal (SSDF) completaron un cuestionario autoaplicado. Se utilizó la prueba de ji cuadrada de Pearson para evaluar las diferencias entre GO y MG. Resultados. Casi todos los participantes (93\%) identificaron elVPH como la causa principal del cáncer cervicouterino. Los GO mostraron un conocimiento más detallado del VPH que los MG, con más probabilidad de haber escuchado de las cepas oncogénicas comunes del VPH $(p=0.000)$. Un $16 \%$ de los médicos contestó incorrectamente que los exámenes de Papanicolaou deben realizarse cada seis meses y 17\% recomendó la histerectomía como una opción de tratamiento para displasia leve o moderada. Conclusiones. Los médicos que se desempeñan en el SSDF demostraron conocimiento básico acerca de la relación entre el cáncer cervicouterino y el VPH. Sin embargo, las normas relativas al tamizaje y manejo son áreas prioritarias para las intervenciones educativas dirigidas a esta población.

Palabras clave: cáncer cervicouterino; virus del papiloma humano; médicos; México

This study was supported by the William and Flora Hewlett Foundation

(I) Program Research Coordinator, Gynuity Health Projects, New York, NY, USA.

(2) Doctoral Candidate, University of North Carolina School of Public Health, Chapel Hill, USA.

(3) Director of Reproductive Health, Population Council, Regional Office for Latin America and the Caribbean, Mexico City, Mexico.

(4) Doctoral Candidate, Johns Hopkins University School of Public Health, Baltimore, MD, USA.

(5) Coordinator, Reproductive Health Program, Secretary of Health, Mexico City, Mexico .

(6) Sub-director of Medical Services, Secretary of Health, Mexico City, Mexico.

Received on: October 21,2005 - Accepted on: February 16, 2006

Address reprint requests to: Population Council, Regional Office for Latin America and the Caribbean,

Escondida II0, col.Villa Coyoacán, 04000, Mexico, City, Mexico.

E-mail: sgarcia@popcouncil.org.mx 
W ith an estimated 500000 new cases and 231000 deaths annually worldwide, ${ }^{1,2}$ cervical cancer is a leading cause of death among women of reproductive age. Eighty percent of all cervical cancer cases occur in developing countries, with Latin America having among the highest incidence rates in the world. The introduction of effective population-based screening programs using the Papanicolaou test to detect precancerous lesions has resulted in a significant reduction in the burden of cervical cancer in the developed world. However, most of the Latin American region has seen little improvement in cervical cancer rates over the past three decades. Despite the existence of a national screening program in Mexico since 1974, the country has had stable mortality rates attributed to cervical cancer of around 17 per 100000 women for roughly the past 30 years. ${ }^{3}$

Since the mid-1990s, clinical evidence has established the human papillomavirus (HPV) as a necessary, though insufficient, cause of cervical cancer. ${ }^{4}$ Knowledge of this causal relationship has spurred research on HPV-based strategies for cervical cancer prevention, including HPV vaccines and the use of HPV testing for follow-up of women with abnormal Pap results or as an adjunct to Pap testing for women over 30. Rapid advancement in research on these topics highlights the need for continuous training of health care providers, who must remain up-to-date on advances in diagnostic and treatment technologies. Furthermore, past studies in diverse settings have demonstrated the utility of continuing medical education with respect to cervical cancer prevention. ${ }^{5,6}$

Limited research, however, has been carried out to explore Mexican providers' knowledge, attitudes and practices about cervical cancer and HPV. A 1998 study of health care professionals in the state of Morelos found that $40 \%$ of obstetrician-gynecologists (ob/ gyns) were unaware of the link between HPV and cervical cancer. ${ }^{7}$ In 2002, the Population Council conducted a national survey of public and private sector general practitioners (GPs) and ob/gyns to assess the current state of knowledge and practices related to cervical cancer and HPV screening, treatment, and counseling. Although roughly $80 \%$ of physicians surveyed knew of the HPV-cervical cancer link, many lacked detailed knowledge about this association. ${ }^{8}$

In the present study, we sought to assess public sector Mexico City providers' knowledge and practices related to cervical cancer and HPV screening, counseling and treatment Norms. This study complements the 2002 national physician survey cited above but used a slightly longer, more detailed questionnaire focusing specifically on GPs and ob/gyns in Mexico City.
All participants were employed by one of 15 public sector hospitals affiliated with the Federal District Secretary of Health (SSDF, for its acronym in Spanish). The SSDF consists of 26 public hospitals in total; 16 offer general gynecology or maternal/child health services and 11 offer pediatric/neonatal care. There are also 215 SSDF health centers throughout Mexico City, Mexico's capital, and the system employs roughly 100 GPs and $168 \mathrm{ob} /$ gyns. SSDF operates 12 dysplasia clinics, and an estimated 200000 Pap tests are performed in its facilities annually. The population served is predominantly lower to middle income without private insurance or insurance through a government job.

\section{Materials and Methods}

This study was carried out between March and April, 2003 in 15 of the 16 public, SSDF hospitals in Mexico City that offer maternal/child health and gynecological care. As part of data collection, the coordinator of the SSDF's Reproductive Health Program obtained a registry of all staff ob/gyns and GPs working at each hospital and delivered a batch of pre-numbered questionnaires to the facility's department head, who distributed them among his staff. Physicians were told that the questionnaire was confidential and that the results would be used in part to inform provider trainings and educational interventions. A fieldworker returned one week later to collect the completed questionnaires from each hospital and deliver them to the offices of the Population Council for data entry and analysis. This study complied with the Population Council's Institutional Review Board procedures, including those for guaranteeing informed consent. Because of our desire to safeguard anonymity, oral informed consent was obtained from all participants, who were informed that the survey was anonymous and confidential.

The questionnaire was self-administered and took between 20-30 minutes to complete. It consisted of 54 questions covering the following topics: physicians' socio-demographic characteristics; cervical cancer etiology and screening protocols; HPV diagnosis and management; and practices regarding patient counseling on HPV. The survey instrument was piloted and developed in collaboration with Mexico City gynecologists and oncologists. Pearson's chi-square tests were used to assess differences in knowledge and practice between ob/gyns and GPs.

\section{Results}

Of the $288 \mathrm{ob} /$ gyns and GPs surveyed, 191 returned completed questionnaires, yielding a response rate of 
$66 \%$. Four of the 191 questionnaires were excluded from the analysis as over half of the questions were left unanswered. The final sample included $109 \mathrm{ob} /$ gyns and 78 GPs working in 15 SSDF hospitals.

Table I shows physicians' socio-demographic and professional characteristics by type of provider. Nearly $60 \%$ of respondents were ob/gyns. Providers' average age was 45 (range $32-78$ years), $67 \%$ were male, and $79 \%$ were married. Three-quarters of both ob/gyns and GPs had graduated from the publicly-funded National Autonomous University of Mexico. Ob/gyns were more likely than GPs to report working in the private sector in addition to the SSDF ( 43 vs. $28 \%, p=.044$ ).

Because several of the survey questions referred to physicians' practices and opinions on treatment of cervical dysplasia and cancer, we asked how often providers treated women with these conditions in SSDF hospitals. Not surprisingly, ob/gyns were significantly more likely than GPs to report that they "regularly" managed these diagnoses ( $30 v$ vs. $8 \%, p=.000$ ), and were also more likely than GPs to have performed a colposcopy, hysterectomy, cone biopsy, and electrosurgery in the last two months. Roughly similar proportions of ob/gyns and GPs (65 and 59\%, respectively) reported having done a Pap test in the past two months.

\section{Cervical cancer screening: knowledge and practices}

The majority of respondents had either been informed about or had read the official Mexican Norms regarding cervical cancer (Table II). With respect to cervical cancer prevention and detection, current official Mexican Norms recommend that women be screened every three years given two normal Pap tests of no more than a year apart and in the absence of HPV infection. Despite these recommendations, $16 \%$ of all respondents stated that Pap tests should be repeated every six months, regardless of the previous result. $\mathrm{Ob} /$ gyns were more likely than GPs to recommend a one-year interval between Pap tests in the event of a prior normal result. Nearly all physicians considered it necessary that women continue screening after menopause.

Nearly all physicians (93\%) correctly identified HPV as the principal cause of cervical cancer. However, providers had less accurate knowledge of the natural history of cervical cancer; $49 \%$ of ob/gyns and $65 \%$ of GPs incorrectly said that without treatment, all cases of cervical intraepithelial neoplasia (CIN) I and II eventually progress to invasive cancer ( $p=.002)$. Ob/gyns were more likely to know that dysplasia or micro-invasive lesions generally progress to invasive cancer over a long
Table I

SOCIO-DEMOGRAPHIC AND PROFESSIONAL

CHARACTERISTICS BY TYPE OF PHYSICIAN,

Federal District Secretary of Health, Mexico, 2003

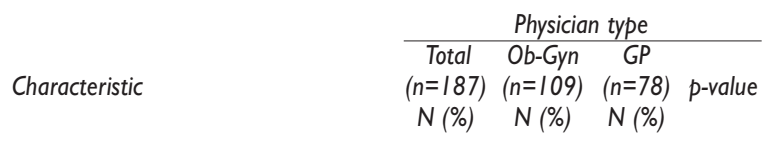

Age

\begin{tabular}{lrrrr} 
Under 40 & $2 I(12)$ & $17(16)$ & $4(6)$ & 0.074 \\
\hline $40-49$ & $112(64)$ & $66(64)$ & $46(66)$ & \\
\hline 50 and older & $4 I(24)$ & $21(20)$ & $20(29)$
\end{tabular}

Sex

$\begin{array}{lrlll}\text { Male } & 117(67) & 73(72) & 44(60) & 0.096\end{array}$

Civil status

Married/cohabitating $\quad 132(79) \quad 80(79) \quad 52(78) \quad 0.805$

Other (single, widowed, divorced) $36(2 \mathrm{I}) \quad 2 \mathrm{I}(2 \mathrm{I}) \quad$ I5 (22)

\begin{tabular}{|c|c|c|c|c|}
\hline Medical school & & & & \\
\hline UNAM & $14 \mid(75)$ & $83(76)$ & $58(74)$ & 0.358 \\
\hline IPN & $23(12)$ & II (I0) & $12(15)$ & \\
\hline Other public & $20(\mathrm{II})$ & $12(\mathrm{II})$ & $8(10)$ & \\
\hline Other private & $3(2)$ & $3(3)$ & $0(0)$ & \\
\hline
\end{tabular}

Year completed medical training

\begin{tabular}{lrrrr}
$1990-1999$ & $17(10)$ & $11(11)$ & $6(8)$ & 0.220 \\
\hline $1980-1989$ & $110(62)$ & $68(66)$ & $42(57)$ & \\
\hline $1940-1979$ & $50(28)$ & $24(23)$ & $26(35)$ & \\
\\
$\begin{array}{l}\text { Duties } \\
\text { Department head }\end{array}$ & $36(20)$ & $19(18)$ & $17(23)$ & 0.303 \\
\hline Staff physician & $137(76)$ & $84(79)$ & $53(71)$ & \\
\hline Other & $8(4)$ & $3(3)$ & $5(7)$
\end{tabular}

Sector of practice

$\begin{array}{llllll}\text { Only in public sector (SSDF) } \quad 118(63) & 62(57) & 56(72) & 0.044\end{array}$

In both public and private sector 68 (34) $46(43) \quad 22(28)$

How frequently treat dysplasia or cervical cancer cases

\begin{tabular}{lllll} 
Regularly & $38(21)$ & $32(30)$ & $6(8)$ & 0.000 \\
\hline Sometimes & $68(37)$ & $4 I(38)$ & $27(36)$ & \\
\hline Almost never & $35(19)$ & $23(22)$ & $12(16)$ & \\
\hline Never & $42(23)$ & $1 I(10)$ & $31(4 I)$
\end{tabular}

Procedures performed in last two months-public sector*

\begin{tabular}{lrrrr} 
Pap test & $115(63)$ & $71(65)$ & $44(59)$ & 0.373 \\
\hline Colposcopy & $57(31)$ & $42(39)$ & $15(26)$ & 0.008 \\
\hline Hysterectomy & $53(29)$ & $50(46)$ & $3(4)$ & 0.000 \\
\hline Cone biopsy & $29(16)$ & $23(21)$ & $6(8)$ & 0.017 \\
\hline Electrosurgery & $23(13)$ & $19(17)$ & $4(5)$ & 0.015 \\
\hline None & $47(26)$ & $18(17)$ & $29(39)$ & 0.001
\end{tabular}

* This question allowed for multiple responses 
(rather than short or medium) period of time (84 vs. 63\%, $p=.007)$. In terms of physicians' strategies for keeping updated on advances in cervical cancer prevention and treatment, the most frequently cited source was continued medical training (92\%), followed by medical conferences $(83 \%)$, medical journals $(78 \%)$, the internet $(68 \%)$, and colleagues $(27 \%)$.
The questionnaire also asked about physicians' knowledge of appropriate treatment protocols and common follow-up procedures in Mexico for managing CIN I through III (Table III). Mexican Norms state that CIN I-III should be managed conservatively, namely with cryotherapy, laser surgery, or electrosurgery followed by continued monitoring in the form of cy-

Table II

Physician knowledge and practices regarding Cervical Cancer prevention and treatment, by type of provider, Federal District Secretary of Health, Mexico, 2003

\begin{tabular}{|c|c|c|c|c|}
\hline \multirow{3}{*}{ Variable } & \multicolumn{4}{|c|}{ Physician type } \\
\hline & $\begin{array}{c}\text { Total } \\
(n=187)\end{array}$ & $\begin{array}{l}\text { Ob-Gyn } \\
(n=109)\end{array}$ & $\begin{array}{c}G P \\
(n=78)\end{array}$ & $p$-value \\
\hline & $N(\%)$ & $N(\%)$ & $N(\%)$ & \\
\hline
\end{tabular}

Read or been informed of official Norms on cervical cancer

\begin{tabular}{lcccc} 
Yes & $150(81)$ & $90(83)$ & $60(77)$ & 0.275 \\
\hline No & $36(19)$ & $18(17)$ & $18(23)$ &
\end{tabular}

Recommended age for first Pap test

In late adolescence (16-19) or after first sexual intercourse

After first sexual intercourse (regardless of age)

After birth of first child

Other (after menarche, after age 30, etc.)

\begin{tabular}{|c|c|c|}
\hline $24(13)$ & $14(13)$ & $10(13)$ \\
\hline I48 (82) & 89 (84) & 59 (79) \\
\hline $6(3)$ & $2(2)$ & $4(5)$ \\
\hline $3(2)$ & I (I) & $2(3)$ \\
\hline
\end{tabular}

Recommended interval between Paps if previous test normal

\begin{tabular}{|c|c|c|c|}
\hline 6 months & $29(16)$ & $16(15)$ & $13(17)$ \\
\hline I year & $129(7 \mid)$ & $79(75)$ & $50(64)$ \\
\hline 3 years & $22(12)$ & $7(7)$ & $15(19)$ \\
\hline Other ( 2 years, every 2 years if past 2 tests were normal) & $3(2)$ & $3(3)$ & $0(0)$ \\
\hline
\end{tabular}

Women should continue routine Pap testing after menopause

\begin{tabular}{rrrr} 
Yes & $183(98)$ & $106(97)$ & $77(99)$ \\
\hline No & $4(2)$ & $3(3)$ & $I(1)$
\end{tabular}

Women should continue routine Pap testing after hysterectomy

\begin{tabular}{lrrrr} 
Yes, in all cases & $131(71)$ & $85(79)$ & $46(59)$ & 0.010 \\
\hline Yes, only when part of the uterus remains & $50(27)$ & $20(19)$ & $30(39)$ & \\
\hline No & $4(2)$ & $2(2)$ & $2(3)$
\end{tabular}

Principle cause of cervical cancer Human papillomavirus (HPV)

Family history of cervical cancer

Other (herpes virus, don't know)

$165(93)$

\begin{tabular}{rrrr}
$97(93)$ & $97(92)$ & $68(94)$ & 0.659 \\
\hline $8(5)$ & $6(6)$ & $2(3)$ & \\
\hline $5(3)$ & $3(3)$ & $2(3)$
\end{tabular}

Without treatment, all cases of CIN I or CIN II eventually progress to invasive cancer

\begin{tabular}{lrrrr} 
Yes & $101(55)$ & $52(49)$ & $49(65)$ & 0.002 \\
\hline No & $78(43)$ & $55(51)$ & $23(30)$ & \\
\hline Don't know & $4(2)$ & $0(0)$ & $4(5)$
\end{tabular}

Length of time for dysplasia or micro-invasive lesions to progress to invasive cancer

\begin{tabular}{lrrrr} 
Short period of time & $38(21)$ & $15(14)$ & $23(31)$ & 0.007 \\
\hline Long period of time & $136(76)$ & $89(84)$ & $47(63)$ & \\
\hline Don't know & $6(3)$ & $2(2)$ & $4(5)$
\end{tabular}


tology and colposcopy every six months. Cone biopsy was also presented as an option on the questionnaire (and considered a correct answer), as suggested by Mexico City cervical cancer experts consulted during the development of the survey. The majority of physicians surveyed, approximately $88 \%$, correctly said that "repeat pap test and colposcopy" was an option for treating CIN I and II. However, 22\% of ob/gyns, compared to 7\% of GPs incorrectly said that hysterectomy was an option for managing CIN I or CIN II $(p=0.049)$. For CIN III, significantly more ob/gyns than GPs responded that cone biopsy was a management option ( 86 vs. 64\%, $p=.005$ ), as was the case for electrosurgery (77 vs. $48 \%, p=.000$ ).

\section{Cervical cancer counseling}

We asked physicians what information they felt should always be provided to women during regular Pap tests (data not shown). The most common responses included: the relationship between HPV and cervical cancer, the purpose of the Pap test in detecting initial signs of cervical cancer, the relationship between unprotected sex and cervical cancer, the meaning of Pap test results, and the relationship between smoking and cervical cancer. Interestingly, only $44 \%$ of respondents believed that public sector physicians regularly counseled women of reproductive age during Pap tests about how to prevent cervical cancer, whereas $70 \%$ believed that private practice physicians provided this counseling to their patients. Respondents perceived the main reasons for physicians not providing this type of counseling to be: lack of time (62\%), lack of interest (55\%), assuming women already have this information $(50 \%)$, and not knowing what information to give women $(42 \%)$.

\section{HPV knowledge}

Table IV shows respondents' knowledge related to $\mathrm{HPV}$, including its diagnosis and role in cervical cancer development. Following a brief paragraph explaining the relationship between HPV and cervical cancer,* nearly all respondents reported to have previously heard about this association. The survey also included a small number of questions that were intended as markers of more specific HPV knowledge. While most providers were aware that not all HPV infections are symptomatic, ob/gyns were significantly more likely than GPs to know about the more common oncogenic HPV types (93 vs. 69\%, $p=.000$ ) and to correctly indicate that types $16,18,31,33$, and 45 generally do not cause genital warts (40 vs. $21 \%, p=.001$ ).

Interestingly, most respondents believed that an HPV test could be a viable option in Mexico for followup of women with abnormal Pap tests; $69 \%$ of ob/gyns and $75 \%$ of GPs also felt that such a test might be feasible for primary screening, either alone or in combination with Pap testing. Cost was the most frequently cited reason for HPV testing being infeasible in Mexico.

\section{Discussion}

As of 2000, the estimated cervical cancer incidence in Mexico was 40.5 per 100 000, leading to 6650 deaths and making Mexico a country with one of the highest

\footnotetext{
* The paragraph read as follows: HPV is sexually transmitted and is the most common cause of cervical cancer throughout the world. Not all strains of HPV are oncogenic; the most high-risk strains are type 16, 18, 31,33 , and 45 . In some cases the infection disappears on its own and in others it progresses to cancer.
}

Table III

KNOWLedge REgARDing tReATMENT OPTIONS FOR CIN I, II, AND III AMONG SSDF PhySICIANS, Federal District Secretary of Health, Mexico 2003

\begin{tabular}{|c|c|c|c|c|c|c|}
\hline \multirow[b]{2}{*}{ Is an option for management } & \multicolumn{2}{|c|}{ CIN I or CIN II } & \multirow[t]{2}{*}{ p-value } & \multicolumn{2}{|c|}{ CIN III } & \multirow[t]{2}{*}{ p-value } \\
\hline & $\begin{array}{l}\text { Ob-Gyn } \\
N(\%)\end{array}$ & $\begin{array}{c}G P \\
N(\%)\end{array}$ & & $\begin{array}{c}\text { Ob-Gyn } \\
N(\%)\end{array}$ & $\begin{array}{c}G P \\
N(\%)\end{array}$ & \\
\hline Repeat Pap \& colposcopy & $77(86)$ & $55(92)$ & 0.313 & $\mathrm{n} / \mathrm{a}^{*}$ & $\mathrm{n} / \mathrm{a}$ & $\mathrm{n} / \mathrm{a}$ \\
\hline Cone biopsy & $66(73)$ & $48(76)$ & 0.871 & $79(86)$ & $34(64)$ & 0.005 \\
\hline Electrosurgery & $68(76)$ & $30(64)$ & 0.346 & $73(77)$ & $22(48)$ & 0.000 \\
\hline Cryotherapy & $53(63)$ & $30(57)$ & 0.288 & $34(4 I)$ & $15(34)$ & 0.050 \\
\hline Hysterectomy & $17(22)$ & $3(7)$ & 0.049 & $69(7 \mathrm{I})$ & $44(75)$ & 0.449 \\
\hline
\end{tabular}




\section{Table IV \\ Physician knowledge and practices related TO DIAGNOSIS AND TREATMENT OF HUMAN papillomavirus, Federal District Secretary of Health, Mexico, 2003}

\begin{tabular}{lllll} 
& \multicolumn{4}{c}{ Physician type } \\
\cline { 2 - 5 } Votal & Ob-Gyn & $G P$ & p-value \\
$N(\%)$ & $N(\%)$ & $N(\%)$ &
\end{tabular}

Had heard of the relationship between HPV

and cervical cancer before reading paragraph*

\begin{tabular}{rrrrr} 
Yes & $180(98)$ & $106(97)$ & $74(99)$ & 0.517 \\
\hline No & $4(2)$ & $3(3)$ & I (I)
\end{tabular}

Had heard about the more common

oncogenic HPV types before reading the paragraph*

\begin{tabular}{lrrrr} 
Yes & $152(83)$ & $100(93)$ & $52(69)$ & 0.000 \\
\hline No & $31(17)$ & $8(7)$ & $23(31)$
\end{tabular}

Believe that HPV types 16, 18, 31, 33

and 45 also cause genital warts

\begin{tabular}{lrrrr} 
Yes & $105(59)$ & $58(56)$ & $47(62)$ & 0.001 \\
\hline No & $57(32)$ & $41(40)$ & $16(21)$ & \\
\hline Don't know & $17(10)$ & $4(4)$ & $13(17)$
\end{tabular}

Consider all HPV infections to be symptomatic

\begin{tabular}{lrrrr} 
Yes & II (6) & $5(5)$ & $6(8)$ & 0.656 \\
\hline No & I7I (93) & I0I (94) & $70(9 \mathrm{I})$ & \\
\hline Don't know & $2(\mathrm{I})$ & $\mathrm{I}(\mathrm{I})$ & $\mathrm{I}(\mathrm{I})$
\end{tabular}

Procedures utilized in Mexico for the

diagnosis of HPV infection ${ }^{\ddagger}$

\begin{tabular}{lrrrr} 
Pap test & $135(73)$ & $85(79)$ & $50(65)$ & 0.038 \\
\hline Cytopathology study & $\mathrm{I} 18(64)$ & $67(62)$ & $51(66)$ & 0.558 \\
\hline Colposcopy & $169(9 \mathrm{I})$ & $102(94)$ & $67(87)$ & 0.076 \\
\hline DNA test for HPV & $102(55)$ & $58(54)$ & $44(57)$ & 0.643 \\
\hline Other & II (6) & $8(7)$ & $3(4)$ & 0.319
\end{tabular}

Believe an HPV test is a viable option

in Mexico for follow-up of women with abnormal Pap results

\begin{tabular}{lrrrr} 
Yes & $143(80)$ & $79(75)$ & $64(85)$ & 0.167 \\
\hline No & $30(17)$ & $20(19)$ & $10(13)$ & \\
\hline Don't know & $7(4)$ & $6(6)$ & $I(1)$
\end{tabular}

Believe that an HPV test is a viable option

for primary screening either alone or in combination with Pap testing

\begin{tabular}{lrrrr} 
Yes & $129(71)$ & $72(69)$ & $57(75)$ & 0.626 \\
\hline No & $43(24)$ & $27(26)$ & $16(21)$ & \\
\hline Don't know & $9(5)$ & $6(6)$ & $3(4)$
\end{tabular}

* The paragraph read as follows: HPV is sexually transmitted and is the most common cause of cervical cancer throughout the world. Not all strains of HPV are oncogenic; the most high-risk strains are type 16, 18, 31,33 , and 45 . In some cases the infection disappears on its own and in others it progresses to cancer.

$\ddagger$ This question allowed for multiple responses cervical cancer mortality rates in the world. ${ }^{9}$ A particularly distressing aspect of these persistently high mortality rates is the preventability of cervical cancer. Addressing the barriers that prevent women from accessing health services and getting regular Pap tests is a key priority. Given the increasing focus on HPV-based strategies for cervical cancer prevention, qualitative research in Mexico City has begun to explore women's perceptions of linking cervical cancer with a sexually transmitted infection. ${ }^{*}$ Such qualitative research suggests that this knowledge would not prevent women from getting Pap tests. Clearly, a vital complementary focus in the fight against cervical cancer in Mexico should be improving quality of care and physician knowledge and practices regarding screening, management, and counseling, especially as these areas relate to HPV.

This survey of 187 providers practicing in Mexico City's public hospitals points to important areas for continuing medical education related to cervical cancer and HPV. For example, although SSDF physicians generally had good knowledge about Norms related to cervical cancer screening, there was some confusion on the appropriate periodicity of Pap tests. Current Norms recommend that women be screened every three years given two normal Pap tests of no more than a year apart and in the absence of HPV infection. The 2001-2006 Program of Action on Cervical Cancer also states that, given epidemiological evidence, annual or semi-annual screening does little to reduce cumulative cancer rates. Findings from this study may suggest a degree of over-screening in SSDF facilities. Since a large proportion of Mexican women are never screened in their lifetime, this is an important area where both provider education (and outreach activities) could be focused, in order to prevent wastage of resources on women who do not need such frequent screening.

Physicians' knowledge about HPV in this study suggested some improvement when compared to the 1998 survey conducted in Morelos, Mexico, in which $40 \%$ of ob/gyns were unaware of the association between HPV and cervical cancer. ${ }^{7}$ Furthermore, the SSDF physicians surveyed demonstrated slightly better knowledge of the HPV-cervical cancer link as compared with physicians who participated in the Population Council national-level survey carried out

* García SG, Becker D, Tatum C, Aldrich T, Fernandez A. Are Mexican women aware of the link between cervical cancer and the human papillomavirus (HPV)? Findings from a qualitative study. Health Care for Women International. (Manuscript under review). 
in 2003. For example, $93 \%$ of SSDF providers compared with $80 \%$ of providers in the national survey knew that HPV was the principal cause of cervical cancer, and $32 \%$ of SSDF physicians vs. $19 \%$ of providers on a national level were aware that high-risk HPV strains generally do not cause genital warts.

SSDF physicians also performed better than physicians who participated in the national survey on questions related to knowledge of management protocols for mild and moderate dysplasia. While 37\% of Mexican ob/gyns in the national survey incorrectly stated that hysterectomy was an option for treating CIN I and $\mathrm{II}^{10}$ only $17 \%$ of SSDF physicians in the present study said it was an option. Many factors play a role in the decision to perform a hysterectomy, including a woman's age, additional risk factors and likelihood of returning for follow-up screening, desire to continue childbearing, and physicians' own financial incentives. Given the epidemic proportion of hysterectomies in Mexico, ${ }^{8}$ this is still an important area of provider education in the SSDF system.

As in the national survey, both ob/gyns and GPs in our study showed poor detailed knowledge of the association between HPV and cervical cancer and the natural history of HPV. This is a vital area for provider education efforts, especially given rapid advances in international research. Though years away from marketing, current development of HPV tests and vaccines will have important implications for middle-income countries like Mexico, and at least one study has already assessed acceptability for an HPV trial vaccine in the state of Morelos. ${ }^{11}$ Indeed, findings from the Morelos HPV Study, for example, indicate greater sensitivity for HPV testing compared with Pap testing for detecting cervical intraepithelial neoplasia (CIN) 2/3. ${ }^{12}$

One limitation to this study is the fact that we do not know the characteristics of providers who did not respond to the survey, nor their reasons for not participating. In addition, these findings may not be generalizeable to public providers outside of the SSDF system in Mexico City. A potential limitation is that the questionnaire included an informational paragraph on HPV, which may have motivated respondents to go back and change their answer to the question on the most common cause of cervical cancer. We also did not corroborate providers' answers regarding screening and management protocols with actual observations of their practices, which would have useful but beyond the scope and objectives of this survey. Finally, providers were allowed to take the questionnaires home, meaning that they could have looked answers up had they wanted to. However, given that as many as 31\% of GPs admitted to not having heard about the high-risk strains of HPV prior to reading the paragraph, and the large proportion of all physicians who were unaware that these strains generally do not cause genital warts, it is unlikely that the information provided in the informational paragraph greatly influenced answers to these knowledge-based questions.

Given this study's findings, designing educational interventions for providers about HPV should be a priority activity for the SSDF system. Such interventions should perhaps include not only ob/gyns and GPs, but other health care professionals who carry out HPV diagnostic and treatment activities, such as colposcopists, cytologists and pathologists. These programs could be integrated into existing educational activities being conducted in Mexico. For example, in 1999, the Mexican Secretary of Health implemented a new national-level strategy for monitoring quality in cytology services, and in early 2003, the SSDF conducted various activities related to the dissemination of the country's updated cervical cancer Norms. It is clear from both of these interventions that physicians generally appreciate and respond well to continuing medical education. Improving the general knowledge about cervical cancer, as well as promoting correct clinical management among not only SSDF providers but with all physicians is vital to reducing the cervical cancer toll in Mexico.

\section{Acknowledgements}

The authors thank the directors of the SSDF hospitals for their assistance with data collection. We also thank doctors Claudia Díaz, Juan Zinser, and Felipe Santana for reviewing the questionnaire.

\section{References}

I.World Health Organization, http://www.who.int/en/. [Accessed 2003, August 7].

2. Blumenthal PD, Ringers P, McIntosh N, Graffikin L. Innovative approaches to cervical cancer prevention. Medscape Womens Health 200I;6:I.

3. Flores Y, Keerti S, Lazcano-Ponce E, Hernandez M, Bishai D, Ferris DG et al. Design and methods of the evaluation of an HPV-based cervical cancer screening strategy in Mexico:The Morelos HPV Study. Salud Publica Mex 2002;44:335-344.

4. Bosch FX, Lorincz A, Munoz N, Meijer CJ, Shah KV. The causal relation between human papillomavirus and cervical cancer. J Clin Pathol 2002;55:244-265.

5. Lai KQ, Nguyen TT, Mock J, McPhee SJ, Doan HT, Pham TH. Increasing Vietnamese-American physicians' knowledge of cervical cancer and Pap testing: impact of continuing medical education programs. Ethn Dis 2004; I4(3 Suppl I):SI22-SI27. 
6. Ajayo IO, Adewole IF. Breast and cervical cancer screening activities among family physicians in Nigeria. Afr J Med Med Sci 2002;3I (4):305-309. 7.Arillo-Santillan E, Lazcano-Ponce E, Peris M, Salazar-Martinez E, Salmeron-Castro J,Alonso-De Ruiz P. Knowledge of health professionals about the prevention of cancer of the cervix: alternatives to medical education. Salud Publica Mex 2000;42:34-42.

8. Aldrich T, Becker D, García SG, Lara D. Mexican physicians' knowledge and attitudes about the human papillomavirus and cervical cancer:A national survey. Sex Transm Infect 2005;8I (2): I35- I4I.

9. Arrossi S, Sankaranarayanan R, Parkin DM. Incidence and mortality of cervical cancer in Latin America. Salud Publica Mex 2003; 45(Suppl 3):S306-S3I4.
10. Programa de Acción: Cáncer Cérvico Uterino. México: Secretaría de Salud, 2002.

II. Lazcano-Ponce EC, Rivera L,Arillo-Santillan E, Salmeron J. Acceptability of a human papillomavirus trial vaccine among mothers of adolescents in Cuernavaca, Mexico. Arch Med Res 200I; 32:243-247. I2. Flores Y, Bishai D, Lazcano E, Shah K, Lorincz A, Hernandez M. Improving cervical cancer screening in Mexico: results from the Morelos HPV Study. Salud Publica Mex 2003; 45(Suppl 3):S388-S398. 